\title{
Un recorrido por la producción de Louis Althusser: el estructuralismo aleatorio
}

\section{A journey through Althusser's thought: an aleatory structuralism}

\author{
Rodrigo Steimberg*
}

\begin{abstract}
Resumen: El presente escrito recorre algunos de los momentos centrales de la producción teórica de Louis Althusser a los fines de señalar un eje con el que abordar la continuidad de su obra: el rechazo a la contradicción tal y como es planteada por Hegel. Este rechazo lo conduce a impugnar que las contradicciones que fundan el orden social produzcan en su propio seno las figuras que la superarán. A estos fines, se recorren las premisas fundamentales del estructuralismo, del concepto de proceso sin sujeto ni fines y del materialismo aleatorio, propuesta que resume la perspectiva de los escritos últimos de Althusser.
\end{abstract}

Palabras clave: Althusser, Estructuralismo, Materialismo Aleatorio, Contradicción dialéctica

\begin{abstract}
The present paper recaps some of the central moments of the theoretical production of Louis Althusser in order to point out a perspective with which to approach the continuity of his work: the rejection of the contradiction as it is proposed by Hegel. This rejection leads him to contest that the contradictions that found the social order produce within them the figures that will overcome it. To these ends, we will examinate the fundamental premises of structuralism, of the concept of process without subject and ends, and of aleatory materialism, which sums up the perspective of Althusser's later writings.
\end{abstract}

Key words: Althusser, Structuralism, Aleatory materialism, Dialectical contradiction

Recibido: 17 octubre 2017

Aceptado: 12 diciembre 2017

\footnotetext{
* Argentino. Becario posdoctoral de la Consejo Nacional de Investigaciones Científicas y Técnicas con asiento en la Universidad Nacional de Quilmes. Correo electrónico: steimbergr@gmail.com
} 


\section{Introducción}

El trabajo teórico de Louis Althusser se encuentra atravesado por una permanente inestabilidad, un insidioso y renovado desequilibrio ${ }^{1}$. La constante autocrítica que lo habita, la variedad de los temas y pensadores que su producción convoca y la propia trayectoria vital de Althusser han llevado a diversos autores a presentar a su trabajo teórico como una empresa en continua revisión de sus propios fundamentos ${ }^{2}$. Ahora bien, sin perder de vista la pertinencia de este señalamiento a la hora de considerar la obra de Althusser en su conjunto, encontramos, de la mano de intérpretes de su trabajo ${ }^{3}$, que la inspira un hilo conductor, identificable como el tópico sobre el que vuelve la constante autocrítica que el propio Althusser moviliza. Nuestro trabajo pretende explicitar este tópico, tomando por base dos tesis, una planteada por Althusser y la otra por Lucien Sève, para mostrar cómo en los propios términos de la problemática estructuralista, de la que Althusser participa $^{4}$, se presentan algunas de las perspectivas que Althusser desarrolla en sus últimos escritos.

Para exponer cómo en los términos de la problemática estructuralista habitan ya algunas de las tesis que Althusser manifestará en sus escritos postreros, tomaremos un texto de Maurice Godelier en el que el antropólogo pretende demostrar la diferencia entre la dialéctica hegeliana y la marxista. Realizar una lectura del texto de Godelier nos permitirá mostrar las consecuencias del enfoque althusseriano a la hora de pensar la transformación de las estructuras sociales, o, en otros términos, del cambio histórico. Así, trabajaremos sobre el escrito de Godelier porque consideramos que se apropia de la crítica althusseriana a la dialéctica de Hegel para plantear de un modo específico la historicidad de las estructuras sociales. De este modo, a partir de recuperar la perspectiva planteada por Althusser en Para un materialismo aleatorio y en Sobre la relación de Marx con Hegel, pretendemos mostrar que ya en los términos del estructuralismo, en el que Althusser y Godelier hunden sus raíces, se condensa la crítica realizada por Althusser a la dialéctica

\footnotetext{
${ }^{1}$ Balibar, Etienne “¡Vuelve a callarte, Althusser!”, Escritos por Althusser, Buenos Aires, Nueva Visión, 2004, 49-74, pp. 55-56.

${ }^{2}$ Por ejemplo, de Ípola, Emilio, Althusser, el infinito adiós, Buenos Aires, Siglo XXI, 2007; Negri, Antonio, "Maquiavelo según Althusser", Althusser, Louis, Maquiavelo y Nosotros, Madrid, Akal, 2004; Anderson, Perry, Tras las huellas del materialismo histórico, España, Siglo XXI Editores, 2011, 43.

3 Diefenbach, Katja. "Althusser with Deleuze: how to think Spinoza’s immanent cause”. Diefenbach, Katja, S. Farris, y G. Kirn, eds Encountering Althusser: Politics and Materialism in Contemporary Radical Thought, A\&C Black, 2013, 165-184; Romé, Natalia, Avatares de una relación. Algunas notas sobre el vínculo entre ciencias e ideología, en la obra de Louis Althusser, V Jornadas de Jóvenes Investigadores, Instituto de Investigaciones Gino Germani, Facultad de Ciencias Sociales, Universidad de Buenos Aires, Buenos Aires, 2009; Fourtounis, Giorgos. "'An immense aspiration to being' the causality and temporality of the aleatory", Diefenbach, Katja, S. Farris, y G. Kirn, eds. Encountering Althusser: Politics and Materialism in Contemporary Radical Thought, A\&C Black, 2013, 43-60; García del Campo, Javier, "Introducción: Leer a Althusser", ER. Revista de Filosofía, 34/35, 2005, 7-12.

${ }^{4}$ Las referencias aquí son inagotables. Tomamos la de de Ípola porque se aboca a determinar el porqué de la inclusión de Althusser en el estructuralismo. Ver de Ípola, op. cit, 125.
} 
hegeliana, esto es, a lo que identifica como filosofía de la historia. Por lo cual, estaremos en condiciones de mostrar que la crítica a la contradicción hegeliana permite tejer un eje con el cual abordar la continuidad de la producción althusseriana, desde el estructuralismo que fulgura en La revolución teórica de Marx y en Para leer El Capital, hasta las tesis sobre el materialismo del encuentro que habitan Para un materialismo aleatorio.

El escrito constará de tres partes generales. En la primera de ellas, tematizaremos los puntos nodales de lo que Althusser plantea en Para un materialismo aleatorio. Nos detendremos, en particular, en aquellos ejes que estructuran aquello que el materialismo del encuentro, como corriente subterránea, perfora, desequilibra. Esto es, nos enfocaremos en los puntos neurálgicos de aquella filosofía de la cual el materialismo del encuentro se desvía. Una vez esto realizado, pretenderemos mostrar qué puntos condensados en esta propuesta se encuentran en el concepto de proceso sin sujeto ni fines, desarrollado por Althusser como síntesis de lo que Marx toma de Hegel. Por lo cual, cerraremos nuestra primera parte indicando la ilación tejida por Althusser entre este concepto y el materialismo del encuentro.

En la segunda parte, realizaremos una lectura de "Sistema, Estructura y Contradicción en 'El Capital"', de Godelier. Insistiremos en ese texto porque en él Godelier desarrolla la oposición entre la dialéctica hegeliana y la marxiana, oposición que se apoya en los términos de la crítica althusseriana a la filosofía de Hegel. De este modo, intentaremos explicitar cómo la producción althusseriana más arriba revisitada sostiene la diferencia entre una dialéctica materialista y una idealista. Esto es, pretenderemos mostrar que las tesis del materialismo aleatorio, así como el concepto de proceso sin sujeto ni fines, habitan los desarrollos de Godelier y, más específicamente, las consecuencias que éste saca a la hora de pensar la transformación de las estructuras del modo de producción capitalista y la producción de las propias de una sociedad socialista.

En la última parte del presente escrito, concluiremos nuestro recorrido recuperando la perspectiva planteada por Giorgos Fourtounis, quien señala la existencia de un estructuralismo aleatorio, para darle cuerpo a la tesis más arriba sostenida, que indica que las sucesivas reformulaciones y revisiones de la producción althusseriana se encuentra surcada por una temática recurrente, que resplandece tanto en los escritos clásicos de Althusser como en su producción tardía. En otras palabras, nos enfocaremos en el trabajo de Fourtounis para demostrar que, desde el estructuralismo al materialismo del encuentro, la producción de Althusser se encuentra articulada en torno al rechazo a la figura central de la dialéctica hegeliana, la negación de la negación. Este rechazo conduce a Althusser a plantear, desde sus textos tempranos hasta los postreros, que el cambio de una configuración social no brota desde su interior, sino que es el resultado de un encuentro que la trastoca desde el exterior. Por eso nos detendremos en la propuesta de Fourtounis acerca del estructuralismo aleatorio, ya que su propia formulación levanta acta de este eje que persiste a lo largo de la producción althusseriana. 


\section{La corriente subterránea del materialismo aleatorio}

Althusser denomina corriente subterránea del materialismo aleatorio a aquella tradición filosófica que se opone al idealismo, entre el cual se cuenta su inversión, el materialismo especulativo. Por materialismo especulativo Althusser entiende aquel de la Necesidad, del Origen, la Esencia, el Fin y la primacía del sentido sobre la dispersión. Contra el idealismo, ya sea abierto o disfrazado de materialismo, Althusser propone un conjunto de tesis que identifica presentes, de manera lateral, a lo largo de la historia de la filosofía: aquellas que constituyen el materialismo del encuentro.

Althusser, en Para un materialismo aleatorio consagra un conjunto de tesis que recorren sus textos anteriores. Entre ellas, se destaca aquella que afirma que una perspectiva materialista debe pensar el hecho por consumar y no el consumado. Se trata, para la filosofía, de tomar acta del hecho de que el sentido, la causalidad, la necesidad, el fin y todo el ordenamiento del mundo advienen una vez que se produce un encuentro, encuentro que podría no haber ocurrido. Una vez ocurrido el encuentro, este da forma a los elementos que él se conjugaron, que en él prendieron. Sin embargo, no estaba en ellos, en tanto elementos, prefigurado su encuentro; no portaban como potencia una finalidad hacia la que tendían. Es el propio encuentro aleatorio el que los in-forma, el que los constituye como, dice Althusser, átomos. Escribe Althusser: "Puede decirse que el mundo es el hecho consumado en el cual, una vez consumado el hecho, se instaura el reino de la Razón, del Sentido, de la Necesidad y del Fin. Pero la propia consumación del hecho no es más que puro efecto de la contingencia, ya que depende del encuentro aleatorio de los átomos debido a la desviación del clinamen. Antes de la consumación del hecho, antes del mundo, no hay más que la no-consumación del hecho, el no-mundo que no es más que la existencia irreal de los átomos"

Althusser retoma aquí la tesis de Epicuro: el mundo consiste en una infinita lluvia de átomos. En ella irrumpe una desviación mínima, un clinamen (Lucrecio). Este desvío, imperceptible, puede hacer que dos átomos prendan, se enganchen. De este encuentro, si dura, brota la necesidad, el fin, el origen y todas aquellas figuras que el idealismo consagra, tomándolas así, como el orden que se engendra en el desorden, como el resultado que puso en marcha el proceso que los tiene por resultado. Esto es, frente a la posición materialista en filosofía, que se limita a levantar acta de que hubo un encuentro, el idealismo sostiene que el encuentro y el orden que produjo como resultado son el motor del encuentro mismo, son la causa de que el encuentro adviniera. Con esta operación, la posición idealista convierte en anterior lo que es posterior, instalando la figura del Sujeto como el Fin que engendró la Necesidad del encuentro, cuando, otra vez, la posición materialista rechaza toda teleología al sostener que es el propio azar el que da lugar al orden, cuando al chocar dos átomos estos prenden. Indica Althusser: "hay que pensar la necesidad como devenirnecesario del encuentro de contingentes"

\footnotetext{
${ }^{5}$ Althusser, Louis, Para un materialismo aleatorio, Madrid, Arena Libros, 2002a, 34.

${ }^{6}$ Ibid., 60.
} 
La corriente materialista subterránea, que va de Epicuro a Marx, afirma que el encuentro aleatorio antecede todo orden, que él es el principio que indica que no hay principio, que toda cosa es el resultado de un encuentro que no estaba prefigurado ni incubado en ella como potencialidad a realizar. En ese sentido, a lo largo del texto en cuestión Althusser retoma a Wittgenstein para destacar la precedencia del caso - en alemán Fall, homógrafa a caída-, de lo que acaece súbitamente, de la circunstancia por sobre la forma, siendo ésta aquello que adviene como resultado de esa caída. Así, dice Althusser: "Por tanto, tan lejos como podamos remontarnos: «hay»= «siempre ha habido», «siempre-ya-ha-sido»"7. Esto implica que por más atrás que vayamos respecto de lo que tenemos delante, por más lejos que intentemos remontarnos a los fines de encontrar una causa seminal, lo que siempre-yaha-sido es el encuentro aleatorio, el advenimiento producto de la concurrencia de elementos.

El sentido, para Althusser, no opera como una astucia, convocando a los átomos para llegar a advenir. No es el Fin que dirige la conjunción de los elementos; por el contrario, el sentido, la ley, el ordenamiento, es siempre el resultado de un encuentro azaroso que podría no haber tenido lugar. Por eso, resume Althusser, se trata de pensar al orden como un devenir-necesario y no a al azar como aquello que se sustrae a la necesidad, como una excepción. ${ }^{8}$

Con estos argumentos planteados, estamos en condiciones de comprender en qué sentido, para Althusser el materialismo del encuentro rechaza de plano la siguiente tesis: "Toda contradicción, motor de su desarrollo, contiene en sí misma el principio de su superación, de su negación y de la reconciliación entre sus términos contrarios. Es el famoso principio de la Aufhebung hegeliana, la negación de la negación que teórica e infaliblemente promete el Fin de la historia, la reconciliación universal de los contrarios, al final del desarrollo de las formas de la dialéctica histórica". 9

El rechazo de la Aufhebung hegeliana, constante en el trabajo de Althusser, incluso desde sus textos clásicos ${ }^{10}$, tiene lugar puesto que en ella la contradicción engendra en sí lo que la superará. Esto es, la negación de la negación hegeliana, para Althusser, supone que toda forma concibe en su propio seno la figura en la que devendrá. En resumidas cuentas, lleva dentro suyo la necesidad de eliminarse y tomar una forma nueva.

Vista desde los resultados que produce, la negación de la negación hegeliana habilita para Althusser la atribución de una causa final a su desenvolvimiento. Puesto que toda forma produce por su propio despliegue su ruina, puede invertirse el orden de la determinación y ver en este despliegue la realización del fin hacia el que tiende, gobernando así su desarrollo. De hecho, el propio Hegel habilita este tipo de lecturas cuando dice: "Que en el curso del espíritu (y el espíritu es aquel que no solamente se cierne sobre la historia, como sobre las aguas, sino que es quien en ella teje y el único que la mueve) sea la libertad lo

${ }^{7}$ Ibid., 57.

${ }^{8}$ Ibid., 101.

${ }^{9}$ Ibid., 14.

${ }^{10}$ Althusser, Louis, La revolución teórica de Marx. México, Siglo XXI Editores, 2004, 82 y ss. 
determinante, esto es, el desarrollo determinado por el concepto de espíritu, y solo ese concepto sea fin final del espíritu (...) que en la historia haya razón, será, por una parte, una creencia plausible por lo menos, pero, por otra parte, es conocimiento de la filosofía"11.

Para Althusser, que la historia universal hegeliana esté gobernada por un fin hacia el que necesariamente tiende se sigue de la estructura fundamental de la dialéctica. Toda vez que la negación de la negación sea el motor del movimiento, dado que cada figura incuba en sí aquella que la sigue, nos enfrentamos a un proceso necesario, en el que las formas se encadenan unas a otras, producto de que cada fase engendra dentro suyo aquella que la va a superar. Falta entonces, para Althusser, la posibilidad misma de que haya encuentros que den forma a los elementos que con él se conjuntan. Esto es, falta la contingencia que permite el enganche de los átomos, siendo reemplazada por la teleología del proceso. Dice Althusser: "No hay entonces encuentro, pues la unidad precede a los elementos, pues no hay ese vacío necesario para todo encuentro aleatorio" ". Como la negación de la negación opera haciendo de toda configuración la partera de lo que la va a suceder, la unidad se encuentra presupuesta, en vez de estar puesta como un resultado aleatorio de un encuentro que podría no haber tenido lugar. En resumidas cuentas, la necesidad deja de ser pensada como el devenir-necesario producto de la contingencia, para ser la contingencia una forma de la necesidad. Frente a esto, el materialismo aleatorio propone que la contradicción no es motora de su despliegue, que a la hora de pensar la historia no cabe hacer del presente una presencia que “contiene en sí misma el principio de su superación”. En la historia, así, ningún período se descompone a sí, sino que sucumbe producto de un encuentro aleatorio entre elementos que producen una nueva conjunción, una nueva forma histórica.

Ahora bien, la dialéctica hegeliana, y la filosofía de la historia en la que desemboca, contienen para Althusser la necesidad de un sujeto para su desarrollo. Althusser, en este sentido, declara que Spinoza iluminó la trabazón implícita entre la figura de los Fines y la de un Sujeto ${ }^{13}$. Escribe Althusser:

Hegel dio a esta exigencia latente en el concepto de génesis su forma declarada y abierta, su forma conceptual: el final es el inicio, lo que quiere decir que el inicio (origen en sentido estricto, nacimiento de un individuo identificado) contiene ya, si no totalmente formado (en sí y para sí) por lo menos en germen, en sí, el término del proceso de desarrollo (...) la estructura de toda génesis es necesariamente teleológica: si el fin ya está presente, en sí, en germen, virtualmente, etc., desde el inicio-origen, implica que todo el proceso está regido por su final, tiende hacia su fin (pensamiento profundamente aristotélico) ${ }^{14}$.

Hegel invierte de este modo, para Althusser, el orden de la causalidad. Transforma a lo que es resultado en el motor del proceso; hace del fin el principio causal.

\footnotetext{
${ }^{11}$ Hegel, George Wilhelm, Enciclopedia de las Ciencias Filosóficas, Alianza Editorial, Madrid, 1999, 570.

12 Althusser, op. cit., 2002a, 70.

${ }^{13}$ Althusser, Louis. Elementos de Autocrítica, Barcelona, Laia, 1975, 47 y ss.; Williams, Caroline, "Structure and Subject", Dillet, Benoit et al. eds., The Edinburgh Companion to Poststructuralism, Edinburgo, Edinburgh University Press, 2012a, 195.

${ }^{14}$ Althusser, Louis, Escritos sobre Psicoanálisis, México, Siglo XXI Editores, 1996, 75.
} 
Esta misma matriz es la que en el mundo ideológico ubica a la subjetividad como "un imperio dentro de un imperio" $" 15$. El sujeto humano se coloca como el centro del mundo, haciendo a los fines trazados por su voluntad el principio causal de su conducta, cuando esta voluntad se explica solamente como una parte del mundo, determinada por él. De otro modo, así como Hegel hace del fin de todo proceso su origen causal, aquello que lo explica -y de ahí el parentesco con la causa final aristotélica-, en la figura del sujeto se encuentra implícita la misma inversión. En ambos casos se trata de explicar un proceso por su resultado: en el caso de Hegel, por el hecho de que toda determinación encierra su negación, por lo cual el fin al que tiende el proceso existe en ciernes desde su origen, con lo cual se trata de desplegar aquello que estrictamente ya existía desde el comienzo; en el de la subjetividad, por explicar la agencia subjetiva por la libre voluntad de los sujetos, cuando esta se encuentra determinada como resultado por las estructuras sociales de las que son portadores $^{16}$. Así es como, siguiendo a Spinoza, Althusser ilumina la trabazón necesaria entre teleología y sujeto. Puesto de otro modo, así es como muestra que en la Aufhebung hegeliana hay un sujeto que orienta el movimiento dialéctico. Con lo cual, rechazar la teleología implícita en la negación de la negación y con ella la tesis de que la contradicción contiene en sí misma el principio que la va a superar, supone impugnar la necesidad de un sujeto como centro de este proceso contradictorio ${ }^{17}$. Si la negación de la negación, por teleológica, negaba el vacío que es requisito para pensar la contingencia de un encuentro, y toda tesis finalista encierra la postulación de un sujeto como centro, causa, esencia y fin que gobierna un proceso, el materialismo althusseriano, por reponer la primacía de la desviación, impugna la necesidad de que haya un sujeto para o del proceso ${ }^{18}$. Dice Althusser: "el materialismo del encuentro no es el de un sujeto (ya fuese Dios o el proletariado), sino el de un proceso sin sujeto pero que impone a los sujetos (individuos u otros) a los que domina el orden de su desarrollo sin fin asignable"19.

Según Althusser, para Hegel el comienzo es a la vez afirmado y negado. Afirmado como el lugar en el que las sucesivas determinaciones de lo absoluto tendrán lugar; negado porque la propia idea de comienzo señala que lo-que-comienza no puede irrumpir en y de la nada, porque esto supondría que en la nada había ya un ser, con lo cual no era nada y por tanto loque-comienza existía ya de algún modo en aquella nada de la que debía manar. Estrictamente, entonces, en el análisis del comienzo realizado por Hegel, se ve que él consiste en la identidad en la diferencia del ser y de la nada (por eso en Hegel no hay

\footnotetext{
15 Althusser, Louis, “La única tradición materialista [1985]”.Youkali. Revista de las artes y el pensamiento, 4 , Diciembre de 2007, 132-154, p. 135.

16 Williams, op. cit., 203; Althusser, Louis y Étienne Balíbar. Para leer El Capital, México, Siglo XXI Editores, 1985, 194.

${ }^{17}$ Williams, op. cit., 204.

18 Williams, Caroline, “Subjectivity Without the Subject': Thinking Beyond the Subject with / through Spinoza”. Lord, Beth, ed., Spinoza Beyond Philosophy, Edinburgo, Edinburgh University Press, 2012b, 11 27, p. 14.
}

${ }^{19}$ Althusser, op. cit., 2002a, 56. 
Origen. El propio Althusser se encarga de destacar esta circunstancia ${ }^{20}$ ). Ahora bien, justamente porque lo que comienza está ya presente en aquello de lo que se separa para comenzar -la nada-, es que comenzar implica el despliegue de lo que ya existía antes de comenzar, es que todo comienzo se antecede a sí mismo. Así, Hegel rechaza al Origen pero al costo de no perderlo nunca, de que nunca sea abandonado puesto que, nuevamente, loque-comienza existía ya antes de comenzar. De ahí que pueda seguirse el rastro de lo-quecomienza en cualquier punto de su despliegue, por más atrás que vayamos en su proceso de desarrollo. Althusser extiende la consecuencia de este planteo: en el Origen ya estaba actuando el Fin que iba a ser creado en este proceso, dado que cuando intentemos seguir el proceso de engendramiento de lo-que-comienza nos enfrentaremos a que él estaba actuando antes de comenzar, en función de darse su propio nacimiento (por eso, como vimos, Althusser llama genético a este modo de abordar un proceso de creación). Esto que permanece y se reproduce a lo largo de todo el proceso, que es identificable como aquello que estaba en ciernes en el Origen, es lo que Althusser denomina sujeto. Por eso, según Althusser, la propia forma dialéctica encierra postular un fin que actuaba en el origen, tratando al resultado aleatorio de un proceso como su causa final. Esta misma inversión es la que supone atribuir a la voluntad de los individuos, que es resultado, la condición de causa de la agencia social. Esta inversión, así, hace de los individuos sujetos, por tratarlos como la causa final del proceso social.

Pues bien, aquí es donde encontramos la continuidad en la empresa althusseriana. Sin soslayar la autocrítica realizada por el mismo autor, la variedad de las temáticas abordadas y los énfasis en distintos aspectos teóricos, principalmente en torno a la teoría marxista, consideramos que el rechazo a la negación de la negación como figura central de la dialéctica, y por consiguiente la necesidad de replantearla a los fines de producir una filosofía materialista, constituye un hilo en torno al cual Althusser teje su trabajo teórico. Esto es, encontramos en la empresa althusseriana una persistente búsqueda de reformular a la dialéctica para transformarla en una materialista. En torno a esta búsqueda, creemos, es que se puede hallar una continuidad en el trabajo de Althusser, continuidad que inicia con el rechazo a la Aufhebung en La revolución teórica de Marx ${ }^{21}$, atraviesa la postulación del concepto de proceso sin sujeto como la deuda teórica de Marx con Hegel una vez que se hace abstracción del carácter teleológico de la dialéctica hegeliana ${ }^{22}$ y finaliza con la tesis más arriba revisitada, aquella que rechaza que la contradicción contenga en sí el principio de su superación ${ }^{23}$.

De este modo, coincidimos con aquellos autores que señalan que el distanciamiento y la rectificación de las tesis althusserianas no obstan para encontrar un conjunto de

20 Althusser, Louis "Sobre la relación de Marx con Hegel". Jacques D'Hondt, coord., Hegel y el pensamiento moderno. Seminario dirigido por Jean Hyppolite, México, Siglo XXI Editores, 1973, 93-121, p. 112 y ss.

${ }^{21}$ Althusser, op. cit., 2004, 82

${ }^{22}$ Althusser, op. cit., 1973, 116.

${ }^{23}$ Althusser, op. cit., 2002a, 14. 
preocupaciones que persisten a lo largo del trabajo de Althusser ${ }^{24}$. Lo que aquí agregamos es que dicha ilación puede ser capturada, en palabras de Althusser, como el rechazo a que la contradicción contenga en sí aquello que la va a corroer $\mathrm{y}$, entonces, superar. Dice Matheron:

se trata, lo hemos visto, de afirmar la lógica del surgimiento contra la del origen. En este sentido, una ruptura supone el surgimiento de algo que no es presupuesto por nada y, a poco que se esté atento al significado de los términos, puede perfectamente ser entendido como "comienzo absoluto" o "comienzo radical": ese algo sólo puede ser pensado como el encuentro de elementos heterogéneos que no estaban destinados a encontrarse (en caso contrario no se trataría propiamente de una ruptura; y ese es el sentido de la crítica althusseriana a la dialéctica hegeliana ${ }^{25}$.

El trabajo de Althusser, desde sus comienzos, se organiza en torno al rechazo del origen; gravita, en cambio, sobre la afirmación del surgimiento.

\section{Godelier: la dialéctica marxista y el cambio histórico}

Como manifestamos al comienzo de nuestro trabajo, revisitar las posiciones de Godelier en "Sistema, Estructura y Contradicción en 'El Capital"" persigue el doble objetivo de mostrar que: a) la crítica althusseriana a la Aufhebung hegeliana sostiene su desarrollo y, con ella, el modo en el que Godelier presenta cómo piensa la dialéctica marxista el cambio histórico de las estructuras sociales; b) que esta perspectiva se ajusta a los términos de la problemática estructuralista. Así, reunidas ambas afirmaciones, estaremos en condiciones de mostrar que desde una perspectiva estructuralista la transformación de las estructuras sociales viene desde afuera de ellas, como un hecho no engendrado en su interior. Por lo cual, habiendo sostenido la continuidad del trabajo de Althusser a partir del rechazo a la figura hegeliana de la negación de la negación, podremos darle carnadura a la hipótesis que recorre nuestro trabajo, es decir, que de la mano de la crítica a la filosofía de Hegel, la producción althusseriana supone, desde el estructuralismo al materialismo del encuentro, pensar al cambio histórico como una transformación que se produce de forma aleatoria y por lo tanto discontinua, sin ser el resultado de contradicciones incubadas en el seno de las estructuras que se modifican.

Diversos autores señalan que Godelier participa, en Sistema, Estructura y Contradicción en El Capital, de la problemática estructuralista ${ }^{26}$. Pues bien, esta participación ocurre en torno a tres momentos fundamentales. El primero de ellos, es aquel en el que Godelier sostiene que Marx: "Hace explícitas las funciones de un elemento en el seno de una estructura o de

\footnotetext{
${ }^{24}$ Romé, op. cit., 11; Fourtounis, op. cit., Matheron, François. "La recurrencia del vacío en Louis Althusser”. Er. Revista de filosofía, 34-35, 2005, 51-74.

${ }^{25}$ Matheron, op. cit., 59.

26 Timpanaro, Sebastiano, "Structuralism and Its Successors" Contemporary Literature, 22: 4, 1981, 600-622; Aquino, Dayani, Os desdobramentos das contradições do processo de reprodução do capital: elementos para o entendimento das crises. Disertación presentada para la obtención del título de Magíster, Universidad Federal de Paraná, 2007; Malavé Mata, Héctor, “Aproximación a los conceptos de Estructura, Superestructura y Sistema” El Trimestre Económico, 37: 146(2), Abril-Junio 1970, 359-403.
} 
una estructura en el seno de un sistema y explica el orden de estas funciones"27. Aquí Godelier, en consonancia con lo que según Lévi-Strauss el programa estructuralista especifica $^{28}$-por lo demás, en el texto en cuestión Godelier toma a Lévi-Strauss como el representante del estructuralismo que permite mostrar la familiaridad entre éste y el trabajo de Marx- y en sintonía plena con la propuesta de Althusser y Balibar en Para leer El Capital $^{29}$, afirma que el análisis de Marx ubica todo elemento dentro de un conjunto de relaciones, así como toda estructura dentro de una mayor, una estructura de estructuras o sistema. Es decir, para Godelier, se trata de mostrar la lógica de funcionamiento de un elemento como parte de una estructura y de una estructura como parte de un sistema. Esta lógica se realiza a través de las relaciones de los elementos entre sí y de las estructuras al interior de un sistema. En la misma línea, en todo sistema hay una estructura que fija los límites de la acción recíproca de las otras, estando estos límites puestos por la posibilidad de que el sistema como tal se reproduzca. Es decir, según Godelier las estructuras que componen un sistema poseen una cierta "compatibilidad estructural" 30 , un umbral que estipula la variabilidad de sus posibles articulaciones sin que el sistema como tal se altere. Esta compatibilidad es establecida por el accionar de la estructura fundamental del sistema $^{31}$.

Una segunda línea argumental que para Godelier comparten el análisis estructural y el marxiano es hacer de las estructuras mecanismos sistemáticos que no se presentan tal y como son en las relaciones visibles. Las estructuras, tanto para Marx como para LéviStrauss: "No se confunden con las 'relaciones sociales' visibles, sino que constituyen un nivel de la realidad, invisible pero presente más allá de las relaciones visibles" 32 . Justamente porque las estructuras se ocultan, la tarea de la ciencia es romper con las evidencias visibles, espontáneas, que se presentan en la práctica de los individuos. Tanto Marx como Lévi-Strauss insisten en que las estructuras constituyen los principios ocultos que explican el funcionamiento del sistema, así como permiten comprender por qué este sistema se presenta de forma disimulada ante las representaciones de los individuos ${ }^{33}$.

Por último, las estructuras, en tanto conjunto de relaciones invisibles que dotan de funciones y caracteres específicos a los elementos que las conforman (lo cual se repite para el análisis de los vínculos entre estructuras), demandan que antes de explicar su génesis histórica sea explicitada su lógica de funcionamiento: "En consecuencia, analizar la génesis histórica de una estructura es analizar las condiciones de aparición de sus elementos internos y de su puesta en relación. La historia económica supone pues, para constituirse,

${ }^{27}$ Godelier, Maurice, "Sistema, Estructura y Contradicción en 'El Capital'”, Puoillon, Jean. et al. Problemas del estructuralismo, México, Siglo XXI Editores, 1975, 50-93, p. 82

${ }^{28}$ Godelier, op. cit., 52; Lévi-Strauss, Claude, Antropología Estructural, Buenos Aires, Eudeba, 1968, 251252.

${ }^{29}$ Althusser y Balibar, op. cit., 193.

${ }^{30}$ Godelier, op. cit., 66.

${ }^{31}$ Aquino, op. cit., 9.

${ }^{32}$ Godelier, op. cit., 52.

${ }^{33}$ Ibid., 54. 
que se identifiquen estos elementos y esta relación, es decir, supone la teoría económica"34. Este énfasis en la elucidación de la lógica estructural del sistema como requisito del análisis histórico ubica a Marx para Godelier por fuera de todo historicismo, ya que subordina el estudio diacrónico al estructural o sistemático. Incluso Godelier sostiene que en este punto Marx anticipa a Saussure y a Lowie ${ }^{35}$.

Como dijéramos al comenzar nuestro trabajo, tomamos el texto de Godelier porque presenta con precisión qué consecuencias se siguen de un enfoque estructuralista, del que participa Althusser, a la hora de pensar la transformación social. De lo que se trata, para nosotros, es mostrar que el escrito de Godelier sigue la crítica althusseriana a la dialéctica como requisito de abordaje acerca de la transformación estructural. Esto es, se trata de mostrar que Godelier acompaña las tesis althusserianas acerca de Hegel -aquellas que, decimos, son las que permiten plantear una continuidad a lo largo de su trabajo- y parte de ellas para pensar la historicidad de las estructuras sociales en el marco del estructuralismo ${ }^{36}$.

Godelier se pregunta: "En efecto, ¿cómo conciliar la hipótesis de la aparición de contradicciones internas en un sistema con la tesis de que el funcionamiento de este sistema reproduce necesariamente sus condiciones de existencia?" 37 . La cuestión pasa por elucidar cómo puede conjugarse el hecho de que un sistema reproduzca sus propias condiciones con que broten en él contradicciones. Godelier, entonces, plantea la existencia de dos tipos de contradicciones: una interna a las estructuras y otra exterior, entre estructuras. La primera, bajo el modo de producción capitalista, ocurre entre el capital y el trabajo. Pertenece, por tanto, a la estructura de las relaciones de producción, que son antagónicas. Sin embargo, esta contradicción interior a la estructura de las relaciones de producción no alcanza para explicar la necesidad de la transformación del sistema como tal. Para que el sistema deje de reproducirse interviene una contradicción entre estructuras: entre la estructura de las relaciones de producción y la de las fuerzas productivas ${ }^{38}$. Escribe Godelier: "Por tanto, la relación entre estas dos contradicciones muestra que la primera contradicción inherente a las relaciones de producción no contiene en su seno el conjunto de condiciones de su propia solución. Las condiciones materiales de esta solución pueden existir fuera de ella, ya que las fuerzas productivas son una realidad completamente distinta a las relaciones de producción e irreductibles a ellas, realidad que tiene sus condiciones internas de desarrollo y de temporalidad propia" 39 .

\footnotetext{
${ }^{34}$ Ibid., 64.

35 Ibid., 68.

${ }^{36}$ Nuestra hipótesis es que la continuidad en el trabajo teórico de Althusser se sostiene en que ya en los términos del estructuralismo la transformación de las estructuras ocurre como una cuestión aleatoria. Por eso diremos que se trata de un estructuralismo aleatorio, en el que se encuentran formuladas algunas de las tesis a las que Althusser dará forma plena en la década del ochenta.

${ }^{37}$ Godelier, op. cit., 64.

${ }^{38}$ Godelier sostiene que esta contradicción entre estructuras no es intencional, no resulta del proyecto de algún sujeto ni de la meta que una clase se traza. Por lo tanto, no es la realización de la acción intersubjetiva de los agentes. Se trata, por el contrario, de las propiedades objetivas de una estructura.
}

${ }^{39}$ Ibid., 79. 
La contradicción entre estructuras no se desarrolla por el desenvolvimiento de una contradicción interior a una estructura. Ahora bien, aun así, podría pensarse que la contradicción entre estructuras es interior al sistema como tal, tomado en su totalidad. Y Godelier escribe la "contradicción entre las estructuras del sistema económico nace del desarrollo interno de este sistema" 40 , lo cual pareciera dar lugar a dicha hipótesis, haciendo a la contradicción fundamental que engendra la necesidad de la superación del capitalismo una interior al sistema. Sin embargo, no es esta la vía argumental que presenta Godelier. Para explicitar el porqué es menester acompañarlo en su crítica a Hegel, que repite los términos en los que la realiza Althusser.

Godelier sostiene que Marx planteó una noción de contradicción distinta de la de Hegel. Mientras que este último habría afirmado la existencia de los contrarios como idénticos, el primero habría planteado su unidad. La diferencia entre identidad y unidad radicaría en que bajo la primera, la solución de una contradicción se incuba en su interior ${ }^{41}$. Dado que para Hegel los contrarios son idénticos, es menester que cada uno de los polos de la contradicción contenga en sí a su opuesto. Así: "Es necesario que la tesis sea ella misma y su contraria, la antítesis, para que la síntesis se halle ya incluida en sus contradicciones" 42 . Bajo la identidad de los contrarios, los elementos que se contradicen en una estructura -o las estructuras que se contradicen al interior de un sistema-, son, para Godelier, reductibles entre sí, idénticos. Esto es, si toda afirmación es a la vez su opuesto, entonces se encuentra ya presente en ella la síntesis que brotará de su devenir. Luego, la solución a una contradicción aparece en su interior. La identidad de los contrarios, sean estos elementos de una estructura o estructuras de un sistema, conduce a pensar el cambio como brotando del interior, como una solución interior a la propia contradicción. De ahí que Marx, al rechazar la figura de la identidad de los contrarios y reemplazarla por la de su unidad, rechace por consiguiente el modo de plantear la solución a una contradicción que esta identidad supone.

El tono de la crítica es familiar con aquel que indicaba que la dialéctica se encuentra presidida por una causa final. Dice Althusser en esta línea.

Las primeras palabras del comienzo de la Lógica lo dicen: el ser es la Nada. El comienzo establecido es negado: no hay comienzo, ni por tanto Origen. (...) Spinoza, como Hegel, rechaza toda tesis del Origen, de la Trascendencia, del «Más Allá», aun cuando aparezca disfrazada en la interioridad absoluta de la Esencia. Pero esta diferencia (pues la negación spinozista no es ni mucho menos la negación hegeliana) que en el vacío del Ser hegeliano se medita por la negación de la negación, la dialéctica de un Telos (Telos = Fin), que se eleva en la historia a sus Fines: los del Espíritu, subjetivo, objetivo y absoluto, Presencia absoluta en la transparencia ${ }^{43}$.

Althusser concluye que por ser la negación de la negación el movimiento absoluto, el origen es negado para ser restituido. Pero esta restitución no le viene desde fuera, no

${ }^{40}$ Idem.

${ }^{41}$ Ibid., 80; Aquino, op. cit., 12.

${ }^{42}$ Godelier, op. cit., 80.

${ }^{43}$ Althusser, op. cit., 1975, 47-48. 
supone que el origen pueda perderse y no retornar a sí mismo. ${ }^{44}$ Envuelve, por el contrario, la plena necesidad de su retorno enriquecido. Así, todo el proceso dialéctico se encuentra gobernado por la negación de la negación y, por lo tanto, por su punto de partida como el recipiente de todo su movimiento subsiguiente, al que retornará ${ }^{45}$. Por eso, dice Althusser como su Fin. En otras palabras, bajo el impulso dialéctico el fin ya está presente, en germen, desde el origen. Con lo cual, aquello en lo que la contradicción devendrá está encerrado en ella misma ${ }^{46}$. Más aún, Althusser es tajante en su crítica a la negatividad al resumirla como un movimiento en el que toda determinación "está en sí en lo otro de sí",4, abordaje que Godelier retoma aquí de modo idéntico al señalar que para Hegel toda determinación encierra su contrario. Por eso, decimos, la crítica althusseriana a la negatividad sostiene el desarrollo planteado por Godelier ${ }^{48}$.

Frente a la figura de la identidad de los contrarios, Godelier defiende una dialéctica presidida por la unidad de los contrarios. Esta dialéctica, que habría sido la utilizada por Marx, supone que las contradicciones que aparecen en el mecanismo de una estructura manifiestan los límites de esta estructura para reproducirse, pero "tienen en parte sus condiciones de aparición y de resolución en el exterior de esta estructura"49. Así, toda la diferencia entre la identidad y la unidad de los contrarios radica en que, para la segunda, la resolución de una contradicción inherente a una estructura depende de condiciones que no son puestas por esta estructura, que le vienen desde fuera. Y Godelier explicita a renglón seguido que esta vía es la que permitirá dialogar al marxismo con el estructuralismo. Con lo cual, vemos que, en los términos de la problemática estructuralista, el cambio estructural supone la actividad de condiciones exteriores a las propias contradicciones de las estructuras. Así como el materialismo aleatorio, el estructuralismo rechaza que una contradicción contenga en sí las condiciones de su propia superación, brotando esta de su interior. El cambio histórico es pensado, así, como un acontecimiento que no es engendrado en el seno de las estructuras, sino que interrumpe de modo exterior a ellas, que encuentra sus causas por fuera de las estructuras que destruye. Sève resume el punto diciendo: "Para el método dialéctico, la estructura, que detrás de su estabilidad relativo no es más que la configuración transitoria del proceso, tiene dentro de sí misma, en forma de contradicción motriz interna, la necesidad de su propia transformación. Para el método estructural, por lo contrario (...) la estructura es por sí misma invariante, y no halla la necesidad de su transformación más en el tropiezo con límites externos" ${ }^{\text {. }}$.

\footnotetext{
${ }^{44}$ Montag, Warren, "Hegel, sive Spinoza: Hegel as His Own True Other”. Sharp, H. y E. Smith, eds., Between Hegel and Spinoza A Volume of Critical Essays, Continuum, London, 2012, 83-97.

${ }^{45}$ Althusser, op. cit., 2004, 164 y ss.

${ }^{46}$ Ibid., 178.

${ }^{47}$ Idem.

${ }^{48}$ Dice el propio Godelier: “Aquí es donde los análisis de L. Althusser muestran su verdadero alcance. El postulado de la identidad de los contrarios garantiza e todo momento, para Hegel, una solución interna, imaginaria, en las contradicciones internas que analiza, y esta colusión a menuda no es más que una operación mágica e ideológica" Godelier, op. cit., 83.

${ }^{49}$ Godelier, op. cit., 83.

${ }^{50}$ Séve, Lucien, "Método estructural y método dialéctico", Trías, Eugenio. et al., Estructuralismo y marxismo, Barcelona, Martínez Roca, 1969, 108-150. p. 143.
}

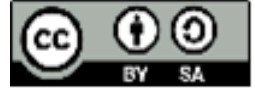


Esta tesis de Sève nos permite pasar a nuestro último acápite. En este punto confluyen estructuralismo y materialismo aleatorio y esta confluencia constituye, para nosotros, la que permite urdir el eje que articula el trabajo de Althusser. Desde el estructuralismo al materialismo del encuentro, se recusa que una contradicción produzca por sí misma la necesidad de su transformación, rechazo que Althusser construye en torno a la negación de la negación hegeliana. Esto nos permitirá sostener en nuestro último acápite que el estructuralismo no se opone a la aleatoriedad, sino que la supone, dándole forma a lo que Fourtunis denomina estructuralismo aleatorio. Pasemos entonces a revisitar el trabajo de Fourtounis puesto que sus tesis explicitan la confluencia de la que aquí hablamos.

\section{El estructuralismo aleatorio}

Hemos sostenido que la ilación del trabajo de Althusser puede ser comprendida a partir de un eje que la vertebra: el rechazo a la figura de la negación de la negación y, con ella, a pensar que las contradicciones de las estructuras sociales producen en su seno las condiciones de su resolución. Esto nos llevó a rastrear esta tesis tanto en el estructuralismo de la década del sesenta, en el que se enmarca el trabajo de Godelier, como en las propuestas acerca del materialismo del encuentro de la década del ochenta, que toman forma en La corriente subterránea del materialismo aleatorio y Filosofía y marxismo. Ahora bien, este trazado que recorre la producción de Althusser es tematizado por Giorgos Fourtounis, quien sostiene que el estructuralismo de cuño althusseriano es uno aleatorio. Es decir, que ya en los términos del estructuralismo Althusser rechaza toda teleología, haciendo lugar a la contingencia y al encuentro como las cifras con las que pensar la transformación estructural.

Fourtounis tematiza el planteo que Althusser realiza acerca del materialismo del encuentro. Se propone defender que el materialismo aleatorio no es una forma de atomismo. Recogiendo la posición althusseriana que indica que antes del encuentro los átomos carecen de toda forma, incluso de la de átomos ${ }^{51}$, Fourtounis sostiene que el materialismo aleatorio no propone la pre-existencia de los átomos como realidades independientes entre sí, realidades que por el clinamen chocarían dando lugar a una estructura. Esto supondría que la identidad de los átomos que caen está dada antes de la desviación y que el resultado del encuentro entre átomos se explica por la interacción entre elementos que preceden al encuentro mismo. Puesto de otro modo, supondría que el resultado del encuentro es una posibilidad inscripta en una combinación determinada entre átomos, puesto que las propiedades individuales de estos átomos preceden al encuentro que producen. De esta forma, se suprimiría la novedad radical que Althusser le adjudica al resultado del encuentro, su imprevisibilidad y, sobre todo, su discontinuidad respecto de la lluvia de átomos anterior al clinamen. Dice Fourtounis: "By the same token, neither the elements nor the structure itself can any longer be thought of as pre-given: the eventual structure is not prescribed in advance, inscribed in some logical space, waiting for the appropriate elements to come and take their allocated places; it cannot be thought of as an abstract possibility,

${ }^{51}$ Althusser, op. cit., 2002a, 34 
before and beyond its actualisation." 52 . Si la estructura resultado del encuentro fuese una posibilidad inscripta en el carácter de los átomos que la componen, entonces el encuentro mismo no produciría nada que no estuviese incubado en la realidad de los átomos. El encuentro se limitaría entonces a realizar posibilidades que lo anteceden, a actualizar potencialidades pertenecientes a la combinatoria de átomos. Por el contrario, Althusser es enfático al señalar que los efectos del encuentro no se encuentran bosquejados, sugeridos o esbozados en los elementos que se encuentran, que "los átomos, lejos de ser el origen del mundo, no son más que la recaída secundaria de su asignación y advenimiento"53. Esto implica para Fourtounis que no existen átomos vírgenes o carentes de forma; todo átomo es siempre-ya un elemento de una estructura, el efecto de una concurrencia que ha durado consiguiendo instaurar el orden en la dispersión. Lo cual supone que, estrictamente, cada encuentro produce un vacío sobre la estructura anterior, convirtiendo a los átomos estructurales en elementos carentes de forma desde el punto de vista de la estructura que advendrá, pero no en sí mismos. Es decir, que solo desde el punto de vista del encuentro por venir es que los átomos carecen de forma. Aun así, este encuentro por venir no se halla inscripto como posibilidad de la estructura en la que él ocurre, por lo cual supone un corte radical con la configuración que interrumpe. Dice Fourtounis: "in that the emergence of a new, structured singularity cannot be explained by any presumably pre-existent cause (...); it requires a new cause, which is not included in those present in the encounter, an absent cause, a new condition that is not included among the initial conditions of the event" 54 .

El vacío en el que ocurre el encuentro no es para Fourtounis una condición a priori, sustancial. No se trata de un telón de fondo que se mantiene mientras en él ocurre la lluvia de átomos. Justamente porque los átomos no son anteriores al encuentro, tal como lo destaca Althusser, el vacío existe desde el punto de vista de la estructura aleatoria que se va a producir como resultado de un encuentro. Solo desde la perspectiva del encuentro que aún no tiene lugar se puede decir que los átomos carecen de forma, puesto que la identidad de estos átomos es siempre-ya el resultado de un encuentro anterior. Así, para Fourtounis, el vacío del que habla Althusser no lo hace caer ni en una filosofía de la nada ${ }^{55}$, ni en el atomismo, que supondría que los átomos preceden al encuentro y, entonces, que aquello que produce este encuentro existe ya como posibilidad de una determinada combinatoria de elementos. Por eso Fourtounis insiste en que para Althusser el vacío no consiste en un

\footnotetext{
52 La traducción nos pertenece: "En el mismo sentido, ni los elementos ni la estructura pueden ser pensados como ya-dados: la eventual estructura no está anunciada, inscripta en algún espacio lógico, esperando a que los elementos apropiados advengan y tomen los lugares ya asignados. La estructura no puede ser pensada como una posibilidad abstracta, anterior y más allá de sus actualizaciones” Fourtounis, op. cit., 48.

53 Althusser, op. cit., 2002a, 57.

54 Nuevamente, la traducción nos corresponde:"'la emergencia de una singularidad estructurada nueva no puede ser explicada por una causa que se presume preexistente (...) esto requiere de una nueva causa, que no está incluida en el encuentro, una causa ausente, una nueva condición que no está incluida entre las condiciones iniciales del evento" Fourtounis, op. cit., 55.
}

${ }^{55}$ Ibid., 56. 
hecho o un objeto, sino en una intervención. Siguiendo a Montag, sostiene que el vacío no es condición del encuentro sino, al revés, el encuentro condición del vacío ${ }^{56}$.

Ahora bien, incluso presentado de este modo, que pareciera chocar con aquel que presenta Althusser, quien afirma que el vacío es condición del rechazo de toda teleología, Fourtounis es enfático respecto del punto que nos interesa: el estructuralismo aleatorio sostiene que la estructura que adviene de un encuentro no se halla inscripta como posibilidad en aquello que interrumpe. Escribe: "In short, in the context of this aleatory structuralism, the aleatory 'taking-hold' of the encounter is the initial and inaugurating moment of the emergent structure's causality, of its retroactive effectivity over the elements and the circumstances of its emergence, the beginning of the emergent entity's structural duration - its history." 57. Y prosigue: "neither the elements nor the structure itself can any longer be thought of as pre-given: the eventual structure is not prescribed in advance, inscribed in some logical space, waiting for the appropriate elements to come and take their allocated places; it cannot be thought of as an abstract possibility, before and beyond its actualisation" 58 . Así como Fourtounis señala que no hay átomos puros, y por eso la insistencia en su carácter siempre-ya estructural, indica que el encuentro produce una novedad radical y aleatoria, no contenida como posibilidad de la estructura en la que ocurre. De este modo reúne el carácter contingente del encuentro con el rechazo del atomismo ${ }^{59}$.

Lo que nos interesa retener de su planteo es que la radical novedad que supone el encuentro, así como su carácter estructural, parten del rechazo de que el evento resulte de contradicciones incubadas en el seno de estructuras anteriores. En otras palabras, tanto el materialismo del encuentro como el estructuralismo rechazan que la transformación estructural se produzca por contradicciones interiores a las estructuras. De ahí su confluencia en el estructuralismo aleatorio. Nuestro punto es que este estructuralismo sintetiza, por recoger, tanto la tesis de Sève como la de Althusser: el estructuralismo sostiene que las estructuras se transforman al chocar con límites exteriores a ellas; el materialismo aleatorio se opone a que toda contradicción contenga en sí su propia negación. Estas dos tesis son, para nosotros, las que dan forma al estructuralismo aleatorio.

Como afirmáramos al principio de nuestro trabajo, nuestro excurso tanto por el escrito de Godelier como por la propuesta de Fourtounis tenía por norte establecer un eje con el que presentar la continuidad de la producción teórica de Althusser. Pues bien, la existencia de un estructuralismo aleatorio resulta, a nuestro modo de ver, la manifestación de esta

\footnotetext{
${ }^{56}$ Idem.

${ }^{57}$ La traducción corre por nuestra cuenta: "En pocas palabras, en el contexto de este estructuralismo aleatorio, la 'toma de consistencia' aleatoria del encuentro es el momento inicial e inaugural de la causalidad de la estructura emergente, de su efectividad retroactiva sobre los elementos y las circunstancias de su emergencia, el surgimiento de la duración estructural de la entidad emergente, su historia" Ibid., 47

${ }^{58}$ La traducción del pasaje es propia: "En el mismo sentido, ni los elementos ni la estructura pueden ser pensados como ya-dados: la eventual estructura no está anunciada, inscripta en algún espacio lógico, esperando a que los elementos apropiados advengan y tomen los lugares ya asignados. La estructura no puede ser pensada como una posibilidad abstracta, anterior y más allá de sus actualizaciones” Ibid., 48.

59 Este énfasis en el carácter siempre-ya relacional de todo elemento, como opuesto a las premisas del atomismo, es el que Fourtounis reivindica del programa estructuralista.
} 
continuidad en torno al rechazo de la Aufhebung hegeliana, cuya consecuencia fundamental es presentar al cambio como el resultado de la negación de sí que toda determinación incuba en su seno. Desde el estructuralismo en el que se enmarca La revolución teórica de Marx hasta las tesis sobre el clinamen que recorren Para un materialismo aleatorio, la producción althusseriana se tensa por la impugnación a que una contradicción sea el motor de su desarrollo, lo cual lo lleva a postular que la transformación de las estructuras no resulta de su propia actividad, sino que se explica por causas exteriores a ellas que las llevan a perecer.

\section{Conclusiones}

Para concluir, nos gustaría insistir sobre algunas de las tesis que hemos formulado en este escrito.

En primer lugar, hemos intentado mostrar un eje con el que atravesar la producción althusseriana. Este eje no solo involucra al estructuralismo y al materialismo del encuentro, sino que perfora también la idea de proceso sin sujeto ni fines $\mathrm{y}$, con ella, la lectura althusseriana de Spinoza. Althusser es explícito al decir que su operación sobre Spinoza tiene por norte producir una dialéctica materialista que recoja la idea de contradicción sin la carga teleológica que sufre en manos de $\mathrm{Hegel}^{60}$. Por lo cual, el concepto de proceso sin sujeto ni fines, que sintetiza su intervención sobre la dialéctica hegeliana ${ }^{61}$, se enmarca dentro de la búsqueda que aquí hemos intentado acompañar y de las consecuencias que esta búsqueda tiene de cara a la teoría althusseriana del cambio histórico.

Por otra parte, nuestra ubicación de Althusser y de Godelier en el marco del estructuralismo procura mostrar que las premisas de este programa de investigación ${ }^{62}$ no suponen denegar la pertinencia de la indeterminación a la hora de pensar la transformación de las configuraciones sociales. Puesto de otro modo, nuestra apoyatura en el trabajo de Fourtounis persigue señalar la unilateralidad de ciertas lecturas del estructuralismo, que lo ubican en franca oposición a la apertura histórica, el azar y los acontecimientos que revolucionan las estructuras sociales. Lecturas como la de Thompson ${ }^{63}$ o la de de Ípola ${ }^{64}$, hacen del estructuralismo un programa infértil a la hora de teorizar la indeterminación de los procesos sociales. Nuestro intento ha sido señalar que, por el contrario, el

\footnotetext{
${ }^{60}$ Althusser, op. cit., 1975; Althusser, Louis, Posiciones, Madrid, Editora Nacional, $2002 \mathrm{~b}$.

61 Steimberg, Rodrigo. Para leer Althusser. De la sobredeterminación al proceso sin sujeto ni fines: la apropiación de Spinoza en la obra de Louis Althusser. Tesis de Doctorado en Ciencias Sociales, Facultad de Ciencias Sociales, Universidad de Buenos Aires, 2016.

${ }^{62}$ Milner, Jean-Claude, El periplo estructural. Figuras y paradigmas, Buenos Aires, Amorrortu, 2003; Steimberg, Rodrigo, El concepto althusseriano de sobredeterminación. Un camino real en la problemática estructuralista. Tesis de Maestría en Ciencias Sociales, Instituto de Desarrollo Económico y Social, Universidad Nacional de General Sarmiento, 2014.

${ }^{63}$ Thompson, Edward, A Miséria da teoría, Rio de Janeiro, Zahar Editores, 1981, 130-132 y 152-153.

${ }^{64}$ de Ípola, op. cit., 133 y 191.
} 
estructuralismo no cancela la contingencia ${ }^{65}$, sino que le hace lugar. Así, mostrar la existencia de un eje que urde la trama del pensamiento althusseriano persigue indicar que estructuralismo y aleatoriedad no son sino dos síntomas de una demarcación, aquella de Althusser respecto de la contradicción hegeliana.

\section{Bibliografía}

Althusser, Louis "Sobre la relación de Marx con Hegel”. Jacques D'Hondt, coord., Hegel y el pensamiento moderno. Seminario dirigido por Jean Hyppolite, México, Siglo XXI Editores, 1973, 93-121.

Althusser, Louis. Elementos de Autocrítica, Barcelona, Laia, 1975.

Althusser, Louis, Escritos sobre Psicoanálisis, México, Siglo XXI Editores, 1996.

Althusser, Louis, Para un materialismo aleatorio, Madrid, Arena Libros, 2002a.

Althusser, Louis, Posiciones, Madrid, Editora Nacional, 2002b.

Althusser, Louis, La revolución teórica de Marx. México, Siglo XXI Editores, 2004.

Althusser, Louis, "La única tradición materialista [1985]".Youkali. Revista de las artes y el pensamiento, 4, Diciembre de 2007, 132-154.

Althusser, Louis y Étienne Balíbar. Para leer El Capital, México, Siglo XXI Editores, 1985.

Anderson, Perry, Tras las huellas del materialismo histórico, España, Siglo XXI Editores, 2011

Aquino, Dayani, Os desdobramentos das contradições do processo de reprodução do capital: elementos para o entendimento das crises. Disertación presentada para la obtención del título de Magíster, Universidad Federal de Paraná, 2007

Balibar, Etienne “¡Vuelve a callarte, Althusser!”, Escritos por Althusser, Buenos Aires, Nueva Visión, 2004, 49-74.

de Ípola, Emilio, Althusser, el infinito adiós, Buenos Aires, Siglo XXI, 2007.

Diefenbach, Katja. “Althusser with Deleuze: how to think Spinoza's immanent cause”. Diefenbach, Katja, S. Farris, y G. Kirn, eds., Encountering Althusser: Politics and Materialism in Contemporary Radical Thought, A\&C Black, 2013, 165-184.

Fourtounis, Giorgos. "“An immense aspiration to being' the causality and temporality of the aleatory", Diefenbach, Katja, S. Farris, y G. Kirn, eds., Encountering Althusser: Politics and Materialism in Contemporary Radical Thought, A\&C Black, 2013, 43-60.

García del Campo, Javier, "Introducción: Leer a Althusser", Er. Revista de Filosofía, 34/35, 2005, $7-12$.

${ }^{65}$ Cosa que señala Perry Anderson. Anderson, Perry, op. cit., 58-59. 
Godelier, Maurice, "Sistema, Estructura y Contradicción en 'El Capital"”, Puoillon, Jean, et al., Problemas del estructuralismo, México, Siglo XXI Editores, 1975, 50-93.

Hegel, George Wilhelm, Enciclopedia de las Ciencias Filosóficas, Alianza Editorial, Madrid, 1999.

Lévi-Strauss, Claude, Antropología Estructural, Buenos Aires, Eudeba, 1968

Malavé Mata, Héctor, "Aproximación a los conceptos de Estructura, Superestructura y Sistema" El Trimestre Económico, 37: 146(2), Abril-Junio 1970, 359-403.

Matheron, François. "La recurrencia del vacío en Louis Althusser". Er. Revista de filosofía, 34/35, 2005, 51-74.

Milner, Jean-Claude, El periplo estructural. Figuras y paradigmas, Buenos Aires, Amorrortu, 2003.

Montag, Warren, "Hegel, sive Spinoza: Hegel as His Own True Other". Sharp, H. y E. Smith, eds., Between Hegel and Spinoza A Volume of Critical Essays, Londres, Continuum, 2012, 83-97.

Negri, Antonio, "Maquiavelo según Althusser", Althusser, Louis, Maquiavelo y Nosotros, Madrid, Akal, 2004.

Romé, Natalia, Avatares de una relación. Algunas notas sobre el vínculo entre ciencias e ideología, en la obra de Louis Althusser, V Jornadas de Jóvenes Investigadores, Instituto de Investigaciones Gino Germani, Facultad de Ciencias Sociales, Universidad de Buenos Aires, Buenos Aires, 2009.

Sève, Lucien, "Método estructural y método dialéctico", Trías, Eugenio, et al., Estructuralismo y marxismo, Barcelona, Martínez Roca, 1969, 108-150.

Steimberg, Rodrigo, El concepto althusseriano de sobredeterminación. Un camino real en la problemática estructuralista. Tesis de Maestría en Ciencias Sociales, Instituto de Desarrollo Económico y Social, Universidad Nacional de General Sarmiento, 2014.

Steimberg, Rodrigo. Para leer Althusser. De la sobredeterminación al proceso sin sujeto ni fines: la apropiación de Spinoza en la obra de Louis Althusser, Tesis de Doctorado en Ciencias Sociales, Facultad de Ciencias Sociales, Universidad de Buenos Aires, Buenos Aires, 2016.

Thompson, Edward, A Miséria da teoría, Rio de Janeiro, Zahar Editores, 1981.

Timpanaro, Sebastiano, "Structuralism and Its Successors" Contemporary Literature, 22: 4, 1981, 600-622.

Williams, Caroline, "Structure and Subject", Dillet, Benoit, et al. eds., The Edinburgh Companion to Poststructuralism, Edinburgo, Edinburgh University subPress, 2012a, 189-206..

Williams, Caroline, “'Subjectivity Without the Subject': Thinking Beyond the Subject with / through Spinoza", Lord, Beth, ed., Spinoza Beyond Philosophy, Edinburgo, Edinburgh University Press, 2012b, 11-27. 